\title{
Closed Loop Throttle Control of a Liquefying Fuel Hybrid Rocket Motor
}

\author{
Timothy Velthuysen ${ }^{1, *} \mathbb{D}$, Michael Brooks ${ }^{1} \mathbb{D}$, Jean Pitot $^{1}$ (D)
}

1.University of KwaZulu-Natal - School of Engineering - Discipline of Mechanical Engineering - Durban, KwaZulu-Natal - South Africa.

*Corresponding author: VelthuysenT@ukzn.ac.za

\section{ABSTRACT}

The thrust produced by a hybrid rocket motor (HRM) can be controlled by varying the oxidizer flow rate to the combustion chamber. This feature is useful in shaping motor thrust profiles and optimizing a vehicle flight trajectory, but propellant throttling in solid-fuel hybrids is limited to the liquid component only, complicating the control scheme and potentially destabilizing combustion in the motor. While hybrid motor throttling ability remains a subject of considerable interest, there has been little investigation of throttling in motors that use high regression rate, liquefying fuels such as paraffin wax. This article describes the development and implementation of a closed loop thrust control scheme for a laboratory-scale paraffin wax/nitrous oxide HRM using a low-cost ball valve as the controlling hardware element. A model of motor performance is first developed from which proportional-integral-derivative (PID) controller constants are obtained through experimental testing. The control scheme is demonstrated through closed loop hot fire tests of a laboratory-scale motor in which thrust tracks a set-point value with feedback provided through a load cell. Upon reaching the setpoint, the motor remains throttled within $\pm 2.4 \%$ of the maximum thrust of the motor. Constant and ramping thrust profiles are demonstrated.

Keywords: Throttling; Thrust control; Ball valve; Paraffin wax.

\section{INTRODUCTION}

Hybrid rockets offer several advantages over conventional solid and liquid rocket systems, including simplicity, safety, less environmental impact and cost effectiveness. They typically consist of one propellant in the solid phase, usually the fuel, and the second propellant in the liquid phase (Sutton and Biblarz 2001). The oxidizer is typically injected into the precombustion chamber and then passes through one or more axial ports in the fuel grain combusting with the fuel vapor during the process. Classical hybrid rocket motors (HRMs) typically have low regression rates resulting in poor performance; however, recent developments in high regressing fuels, such as paraffin wax, show promising market potential (Mazzetti et al. 2016). Throttling the motor and modulating the thrust provides a number of advantages, including an increase in the efficiency of the motor by maintaining an optimum oxidizer-to-fuel $(\mathrm{O} / \mathrm{F})$ ratio and therefore a reduction in the cost of launching these rockets. Throttling a rocket in order to maintain an optimum $\mathrm{O} / \mathrm{F}$ ratio allows for less propellant to be loaded onto the rocket for a given delta- $v$, compared to the same rocket without throttling. Throttling HRMs is also advantageous in optimizing flight trajectories via thrust profile control for executing soft landings and allowing for the launch of sensitive payloads that require low-g loading. Despite these advantages,

Received: Mar. 27, 2020 | Accepted: Nov. 24, 2020

Peer Review History: Single Blind Peer Review.

Section Editor: T John Tharakan

This is an open access article distributed under the terms of the Creative Commons license. 
very little research has been done to date on throttling liquefying fuel HRMs, such as those utilizing a paraffin wax and nitrous oxide $\left(\mathrm{N}_{2} \mathrm{O}\right)$ propellant combination (Ruffin et al. 2017).

Owing to their throttling capabilities, hybrids find use in tactical operations as a significant advantage may be derived through energy management and boost-and-sustain performance regimes. They have been proposed for in-space applications due to throttling characteristics and stop-restart ability (Parissenti et al. 2011). This also makes HRMs a potential candidate for providing the means of both velocity increment for acceleration-sensitive payloads, as well as orbital insertion applications. Another promising application is in thrust augmentation (Spurrier 2016). By making use of throttling, an exoatmospheric trajectory can be shaped for maximum performance and, in addition, there remains the possibility of steering via differential control of individual motors thrust levels (Altman and Holzman 2007). Due to the inherent nature of HRMs there exists a considerable degree of variability between motor thrust profiles that cannot be rectified by manufacturing processes alone. Throttling has been used to minimize this variability in $\mathrm{HTPB} / \mathrm{N}_{2} \mathrm{O}$ HRMs (Whitmore et al. 2014).

Interest in throttling HRMs has increased recently due to the advantages they offer over conventional liquid and solid rocket propulsion systems. In France during the 1960s, ONERA developed a hybrid sounding rocket called Lithergol Experimental (LEX) that used a solenoid valve to throttle the thrust from a $10 \mathrm{kN}$ peak down to $2 \mathrm{kN}$ during flight. Between 1964 and 1967, a total of eight LEX rockets were flown, all successfully (Duban 1968). Around the same time, the United States Air Force (USAF) developed a throttleable hybrid rocket programme for aerial target drones. The programme employed MON-25 (75\% nitrogen tetroxide and $25 \%$ nitric oxide) as an oxidizer and $10 \%$ magnesium and $90 \%$ polymethylmethacrylate as the solid fuel. The motor could achieve a peak thrust of $2.3 \mathrm{kN}$ with an 8:1 turndown ratio (Mead Junior and Bornhorst 1969). A second programme saw the development of a larger motor with a $5.3 \mathrm{kN}$ peak thrust. The motors used a pintle valve actuated by a torque motor and allowed for a turndown ratio of 10:1 (Penn and Branigan 1975). Also during the 1960s, the USA United Technology Centre (UTC) developed several HRMs, including a high-performance motor for use in the upper stage of a launch vehicle (Sutton and Biblarz 2001). This used a hypergolic mixture of a lithium-based fuel and an oxygen difluoride $\left(\mathrm{OF}_{2}\right)$ oxidizer, had a peak thrust output of $22.2 \mathrm{kN}$ and could be throttled with an 8:1 turndown ratio. In the late 1980s, AMROC developed several hybrid motors of various sizes, using mostly hydroxyl-terminated polybutadiene (HTPB) as the fuel and either liquid oxygen (LOX) or $\mathrm{N}_{2} \mathrm{O}$ as the oxidizer (Kniffen et al. 1990). In 1999, Lockheed Martin and National Aeronautics and Space Administration's (NASA) Marshall Space Flight Centre collaborated with the intention of producing a large, single stage HRM to replace the two stage sounding rockets that were in use by the centre. These used HTPB mixed with aluminium as the fuel and LOX oxidizer. They had two branching oxidizer lines that could be turned on and off independently by ball valves to step-throttle the motor. The project ended in 2003 after a series of successful ground static tests (Arves et al. 2003). In collaboration with NASA Ames Research Centre, NASA Wallops and the Space Propulsion Group (SPG), Stanford University developed a custom oxidizer throttling device for the peregrine rocket. (Doran et al. 2009). This design made use of an open loop control regime with predetermined oxidizer mass flowrate values. Throttle ability in $\mathrm{N}_{2} \mathrm{O} / \mathrm{HTBP}$ hybrid rockets have been investigated by Peterson et al. (2012) utilizing a closed loop control regime in conjunction with a lookup table to overcome nonlinearities in the control hardware. More recently, research has been conducted with the objective of further increasing the regression rate of the paraffin wax fuel through a range of methods, such as a specialised injector (Bouziane et al. 2019), configuring the fuel grain in a nested helical structure (Wang et al. 2020), and modifying the chemical composition of the fuel grain (Wu et al. 2018). Although high regression rates are desirable in hybrid rockets, it may present difficulties in throttling due to their more sensitive and transient characteristics compared to slow regression rate fuels. This article proposes a robust method of throttling an HRM that utilizes paraffin wax as fuel and $\mathrm{N}_{2} \mathrm{O}$ as oxidizer using either thrust or pressure values as feedback.

The primary objective of this work is to demonstrate the ability to throttle paraffin wax $/ \mathrm{N}_{2} \mathrm{O}$ HRMs within a small margin of error, with the secondary objective being to demonstrate throttle ability using combustion chamber pressure for potential application in flight vehicles. First, a description of the experimental setup used for testing is given. Thereafter, the control philosophy and the regime used are outlined. Finally, experimental testing results from open loop and closed loop throttle control tests are given, followed by conclusions drawn from the results. 


\section{METHODOLOGY}

The present study, to determine throttling response of hybrid motors utilizing high-regression rate fuels, was carried out in a dedicated test facility of the University of KwaZulu-Natal (UKZN) (Brooks et al. 2010). The battleship lab-scale motor uses $\mathrm{N}_{2} \mathrm{O}$ (CAS No. 10024-97-2) as oxidizer and paraffin wax as fuel, with the wax grain cast into a phenolic-glass fibre thermal liner and slotted into the main stainless-steel combustion chamber and restrained by flanges on either end. The fore-end flange contains the injector bulkhead and the aft-end acts as a retainer for the solid copper nozzle. The wax is cast with a circular port measuring $25 \mathrm{~mm}$ in diameter. Wax properties can be found in Table 1 . Wax was purchased from SASOL Limited and $\mathrm{N}_{2} \mathrm{O}$ from African Oxygen Limited. Figure 1 shows the configuration of the lab-scale motor.

Table 1. Sasol Wax 0907 physical properties (Sasol Wax GmbH 2013).

\begin{tabular}{ccc}
\hline Solidification point $\left({ }^{\circ} \mathbf{C}\right)$ & Oil content $[\%]$ & Viscosity at $100{ }^{\circ} \mathbf{C}\left(\mathrm{mm}^{2} \cdot \mathbf{s}^{-1}\right]$ \\
\hline $83-94$ & $0.0-2.0$ & $8.5-12.5$ \\
\hline
\end{tabular}

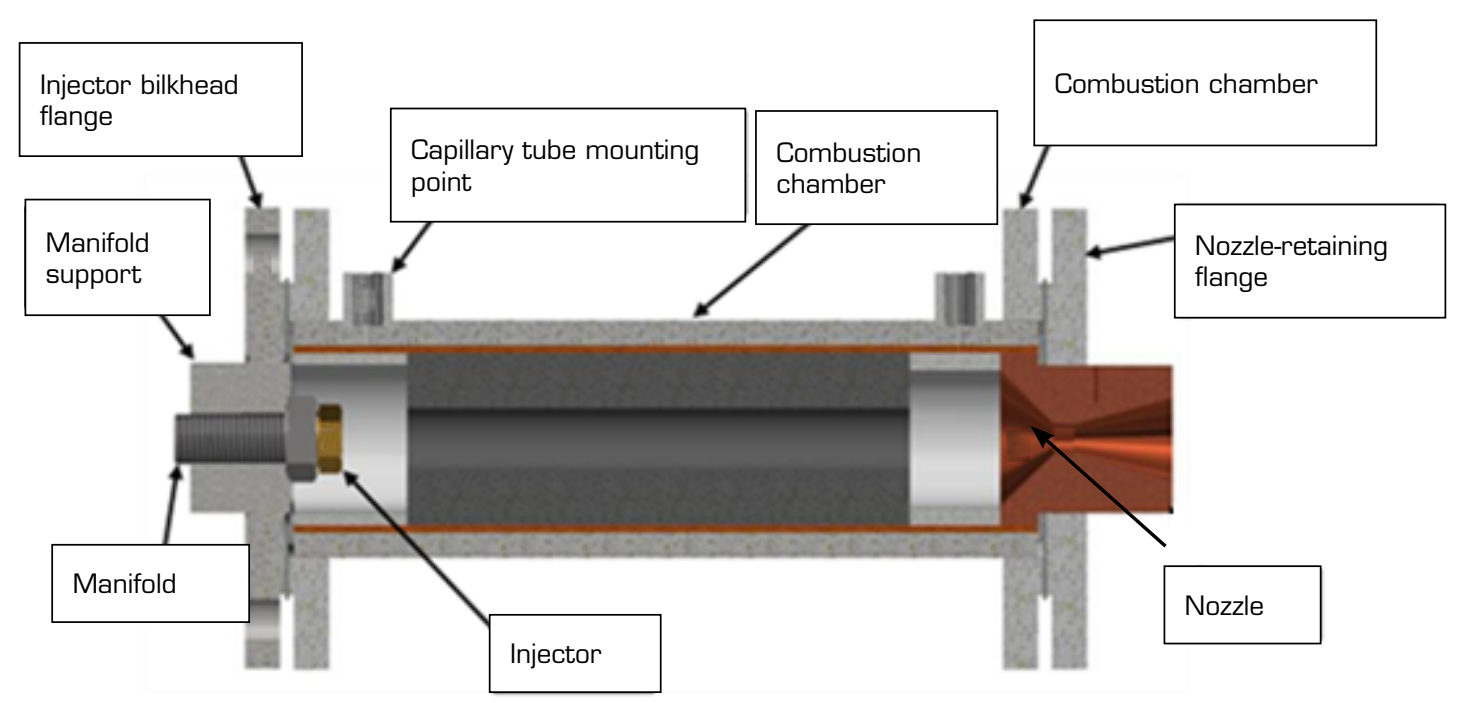

Figure 1. Combustion chamber assembly cross section with inserted fuel grain cartridge. Adapted from Maharaj (2018, p. 24).

Using the homogeneous equilibrium model (HEM) and values for enthalpy from the National Institute Standards and Technology (NIST) Reference Fluid Thermodynamic and Transport Properties Database (REFPROP) program, the injector was redesigned with six holes of $1 \mathrm{~mm}$ diameter, with each hole having a length of $10 \mathrm{~mm}$ to ensure adequate cavitation of the $\mathrm{N}_{2} \mathrm{O}$ and to prevent combustion instabilities. The injector was machined out of a M16 brass bolt, as shown in Fig. 2. During testing, this injector produced an oxidizer mass flow rate of $0.132 \mathrm{~kg} \cdot \mathrm{s}^{-1}$ with no throttling, which resulted in a stable burn. The average pressure drop across the injector was measured to be 21.5 bar.

Oxidizer flow rate was measured using a load cell beneath the $\mathrm{N}_{2} \mathrm{O}$ supply tank. Grain dimensions are shown in Fig. 3. The motor was ignited using a 40/60 (\%wt.) sucrose/potassium nitrate mixture packed into a paper cylinder measuring $15 \mathrm{~mm}$ in diameter and $25 \mathrm{~mm}$ length. The mixture was ignited via a nichrome wire wrapped around the cylinder and connected to a large $12 \mathrm{~V}$ battery. The igniter was placed in the precombustion chamber and positioned to impinge on the wax grain when lit. During the start-up sequence, a relay activates and allows the nichrome wire to burn and ignite the sucrose/potassium nitrate cartridge, thereafter the mixture burns for $3 \mathrm{~s}$ to ensure there is sufficient heat and melted wax to sustain combustion. Once the $3 \mathrm{~s}$ have expired, the valve opens to a predetermined angle. 

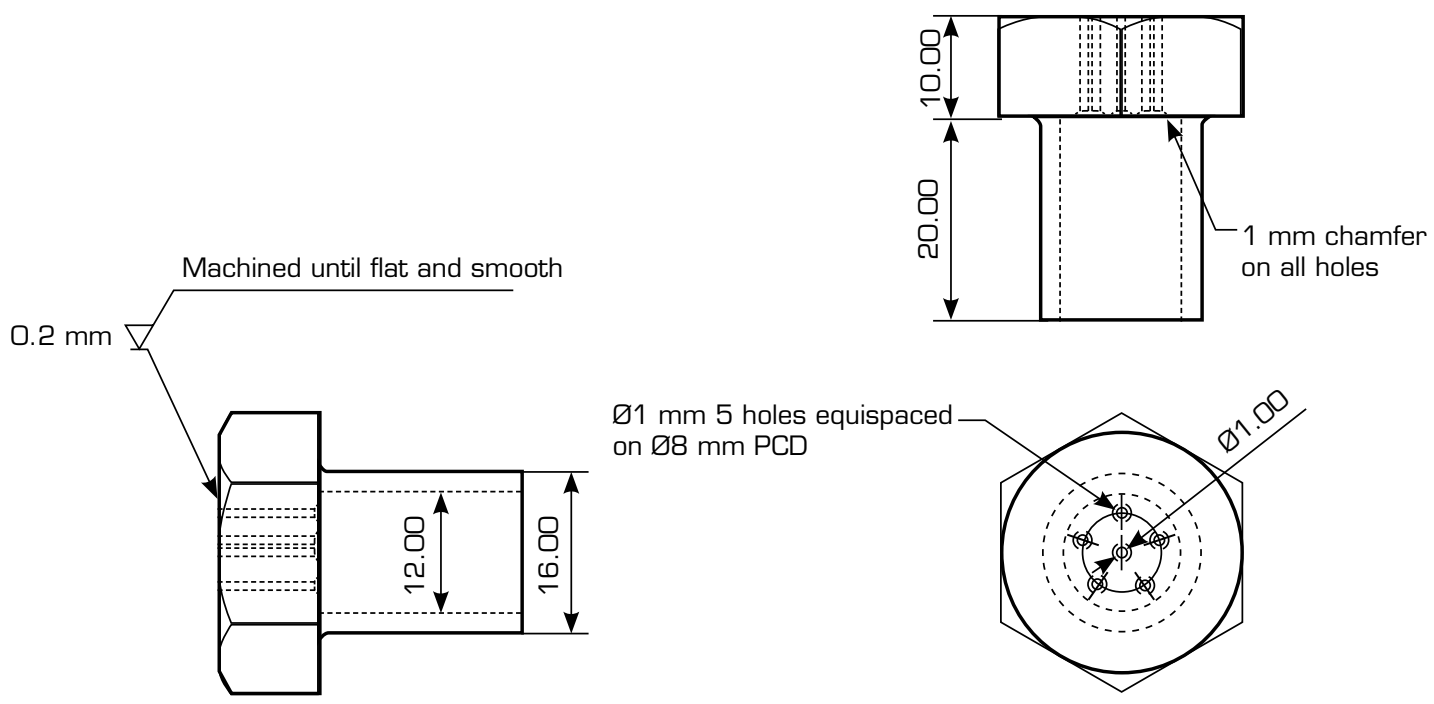

Figure 2. Injector dimensions used on all closed and open loop tests.

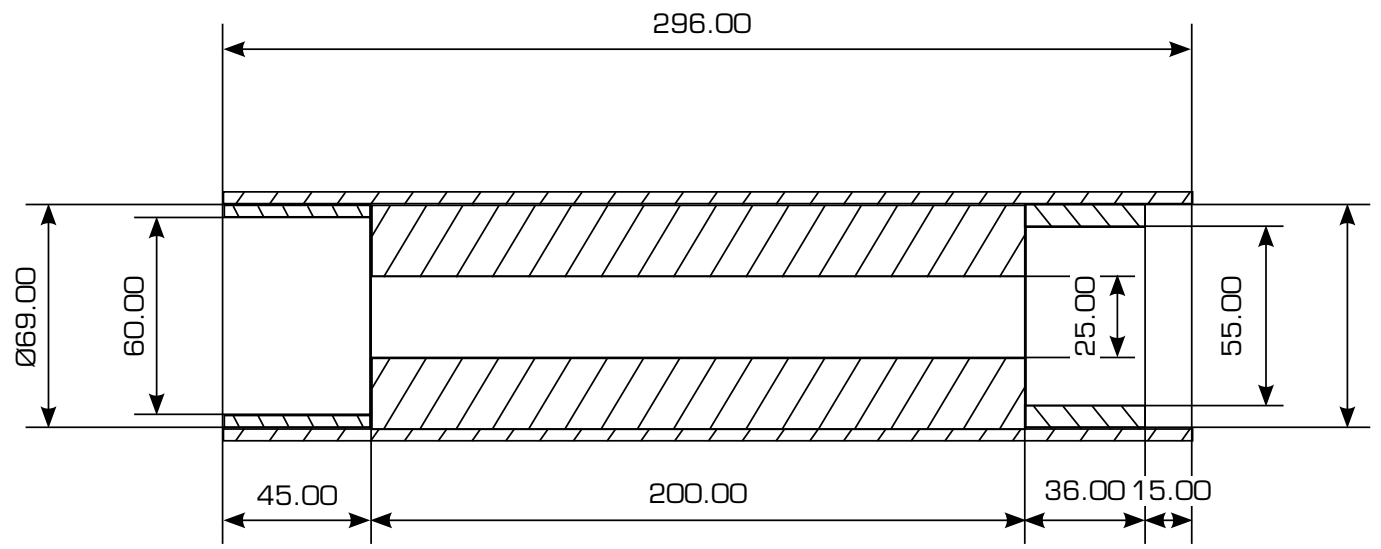

Figure 3. Grain and cartridge dimensions.

The nozzle was machined out of solid copper. The nozzle was inspected after each hot fire test to ensure dimensional integrity between burns; besides for a thin deposit of carbon, no nozzle erosion was detected. Cross-sectional dimensions of the nozzle are shown in Fig. 4.

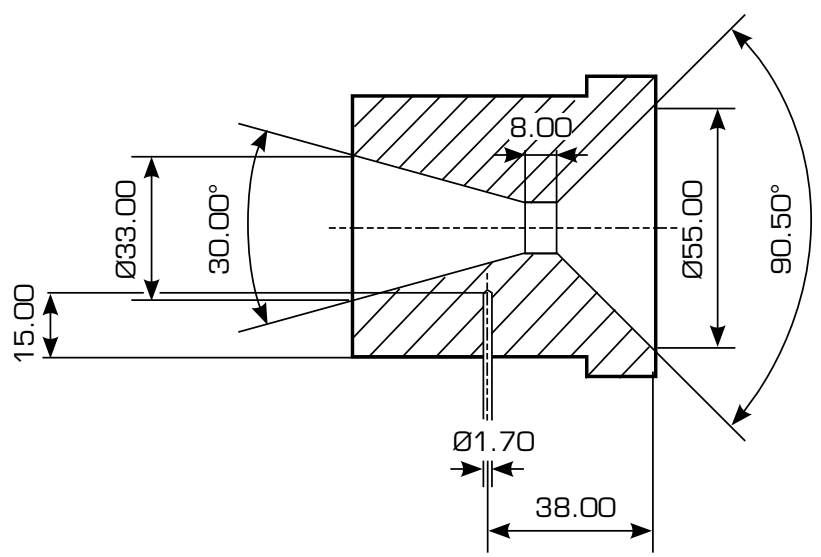

Figure 4. Nozzle cross-section showing detail of thermocouple hole for temperature measurements. Nozzle throat is $12 \mathrm{~mm}$. 
Since this research aims to facilitate the cost-effective manufacture of low-cost hybrid rocket demonstrators, the study was mainly concerned with implementation of an inexpensive and lightweight oxidizer flow control valve that can be transferred from the ground test setup to a flight vehicle with little adaptation. To this end, an inexpensive but robust ball valve was selected to control oxidizer flow rate, in accordance with the thrust command profile. Ball valves exhibit high flow coefficients, are readily available and are relatively inexpensive. They are also highly configurable, easy to clean and maintain, and require only $90^{\circ}$ rotation to fully open from the fully closed position. The ball valve used on the test stand was connected to two DC servo motors by $3 \mathrm{D}$ printed ABS plastic gears on a 2:1 ratio.

Figure 4 shows the lab-scale test stand configuration. To measure combustion chamber pressure, two WIKA A-10 pressure transducers were placed at the pre- and postcombustion chambers (P5 and P6 in Fig. 5), the outputs were summed and averaged to find the average pressure inside the chamber. These transducers are rated to 100 bar with an accuracy of $1 \%$ of the measured span, a nonrepeatability of $0.1 \%$ span, and signal noise accounts for no more than $0.3 \%$ of the measured span.

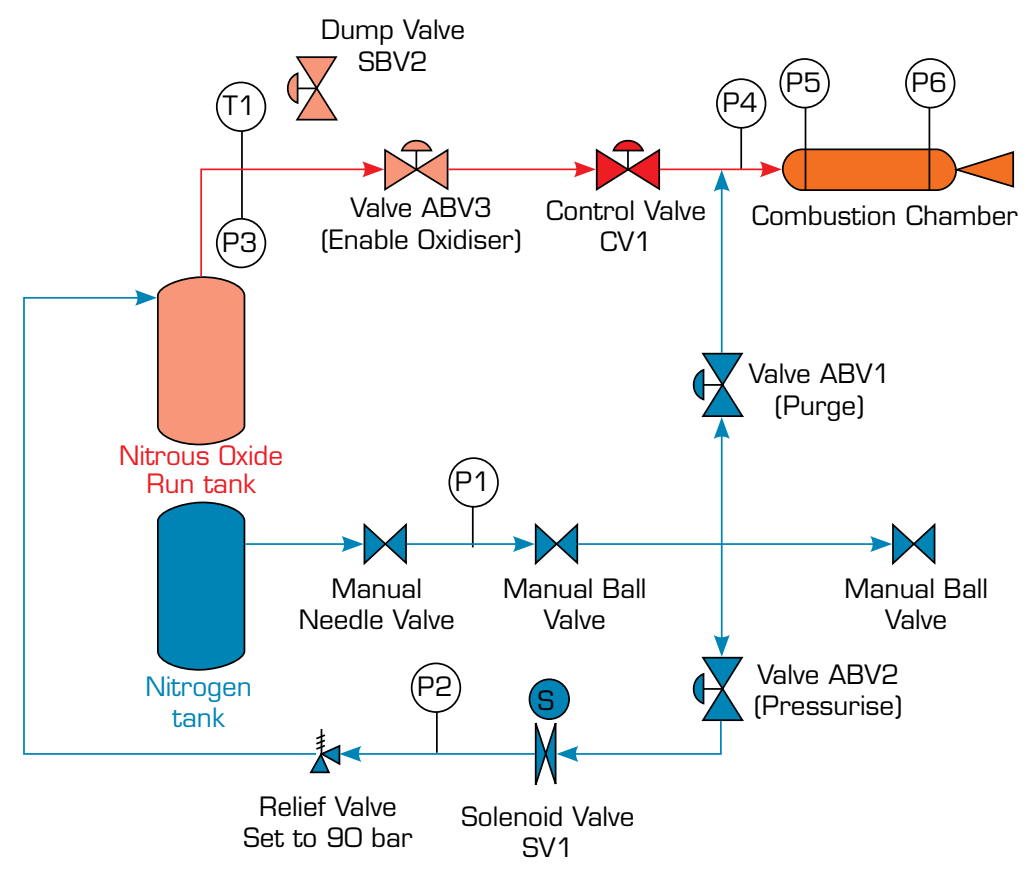

Figure 5. Piping and instrumentation diagram of the lab-scale test stand. The red lines indicate $\mathrm{N}_{2} \mathrm{O}$ flow while the blue lines represent nitrogen flow. The valve labelled CV1 was used as the control valve.

Ball valves are not without disadvantages. A significant drawback for controllability purposes is their nonlinear flow characteristic and, although commercial inserts can impose a more linear flow pattern, these add expense. The nonlinear nature of the ball valve is illustrated in Fig. 6, which shows the projected two-dimensional hydraulic area versus the valve angle. Open loop testing shows that the motor is mostly responsive in the $35-65^{\circ}$ valve angle region, which is also the most nonlinear section. A further shortcoming is occasional sealing malfunction. In addition, the seal on a ball valve can inhibit motion and require a large initial actuation torque, necessitating more powerful actuator/gear assemblies. Despite drawbacks, the low cost of ball valves, their ready availability and easy transferability from a lab-scale stand to a flight vehicle makes them a potentially effective throttling tool worthy of investigation. Control valve characteristics are described in Table 2.

Ball valves this size require relatively large amounts of torque to open and modulate the valve angle. To overcome this, two Savox SV0236MG - High Voltage 1/5 Scale Servo were configured in a two-to-one gear ratio, as illustrated in Fig. 7. The servo-valve subassembly specifications are summarized in Table 3. Although every precaution was taken to ensure minimum play between mechanical components, complete rigidity is impossible. Servo manufacturer claims less than $0.3^{\circ}$ backlash. It was estimated that the resolution/uncertainty between the servos and valve angle was $3^{\circ}$, and so this was chosen as the minimum valve angle travel. 


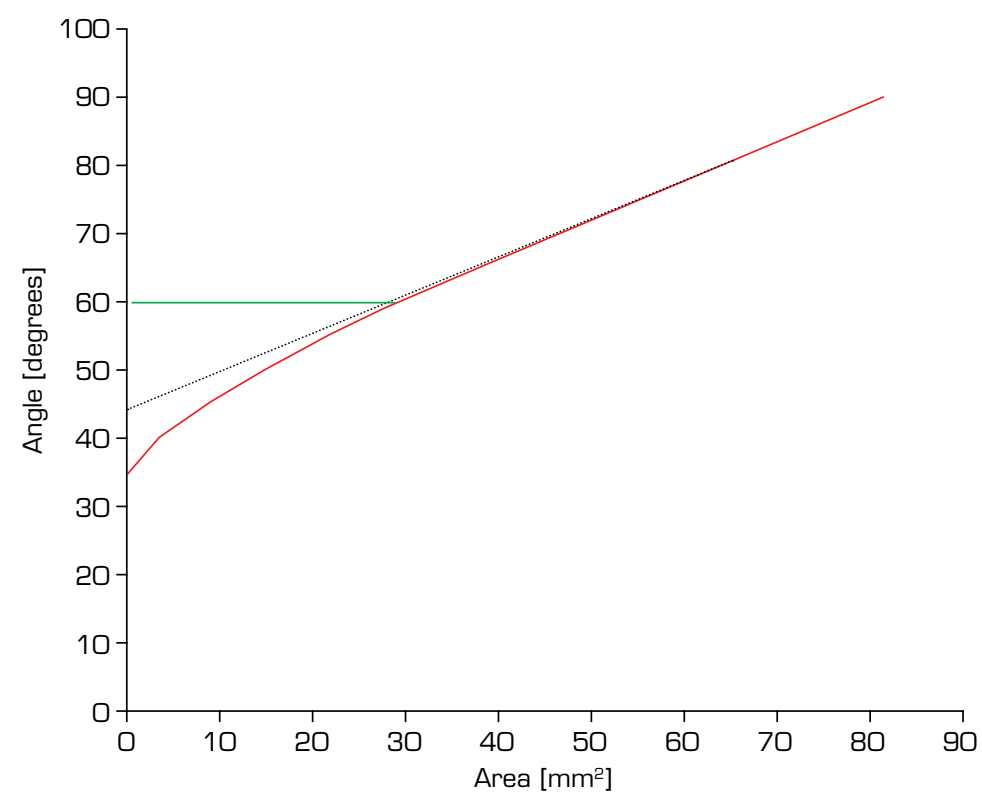

Figure 6. Graph showing the hydraulic area as a function of the angle of the ball valve where $0^{\circ}$ is fully closed and $90^{\circ}$ is fully open.

In Fig. 6 the green line illustrates the point at which the area transitions from a nonlinear relationship to valve angle to a more linear one. The red line represents the relationship between valve angle and hydraulic area. The dotted line is a straight line to illustrate where the relationship becomes linear.

Table 2. Control valve characteristics.

\begin{tabular}{cc}
\hline Valve type & Single piece ball valve \\
\hline Pressure & 172 bar at $37^{\circ} \mathrm{C}$ \\
\hline Port size & $10.3 \mathrm{~mm}$ \\
\hline Material & 316 stainless steel \\
\hline
\end{tabular}

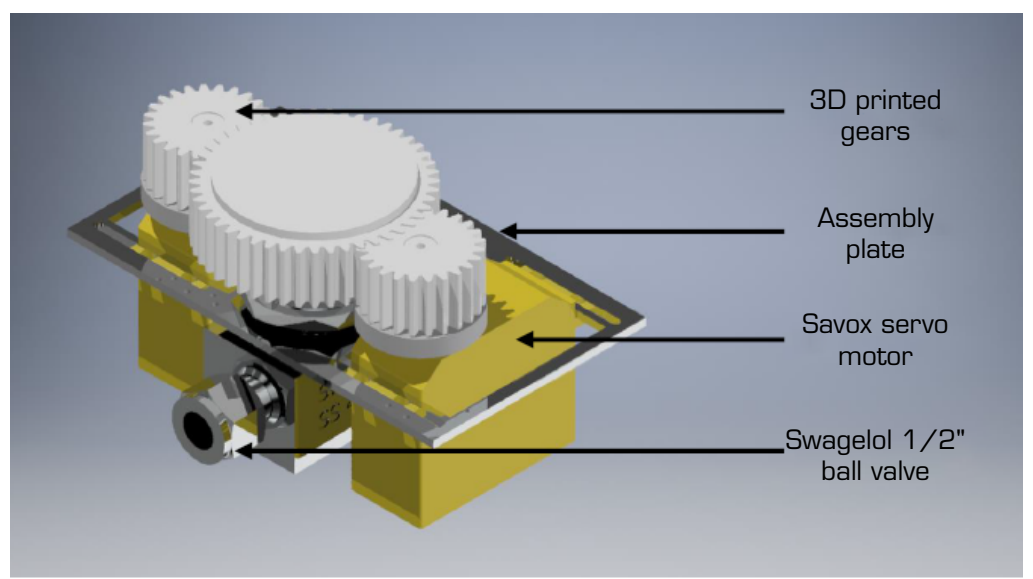

Figure 7. Servo and 1/2-inch control ball valve assembly. Retrieved from Maharaj (2018, p. 40).

The combustion chamber was secured on linear rails with a loadcell attached to the fore-end used to measure thrust output. The load cell used is an Avery Weigh-Tronix T203 super precision beam cell, relevant data is listed in Table 4. 
Table 3. Specifications of control servo-valve subassembly.

\begin{tabular}{ccc}
\hline Parameter & Value & Unit \\
\hline Input voltage & 7.4 & VDC \\
\hline Gearing ratio & $2: 1$ & - \\
\hline Maximum torque delivered to valve stem & 15.69 & $\mathrm{Nm}$ \\
\hline Zero load actuation speed & 0.255 & $\mathrm{~s} / 90^{\circ}$ \\
\hline Actuation speed under load (nominal operating conditions) & 1.5 & $\mathrm{~s} / 90^{\circ}$ \\
\hline Hydraulic flow diameter (fully open) & 10.2 & $\mathrm{~mm}$ \\
\hline Minimum pulse width & 800 & $\mu \mathrm{s}$ \\
\hline Maximum pulse width & 1400 & $\mu \mathrm{s}$ \\
\hline Refresh interval & 20000 & $\mu \mathrm{s}$ \\
\hline
\end{tabular}

Source: Maharaj 2018.

Table 4. Selected specifications of Avery Weigh-Tronix T203 load cell used in this study.

\begin{tabular}{cc}
\hline Rated output & $1.75 \mathrm{mV} / \mathbf{V} \pm \mathbf{0 . 0 1 \%}$ \\
\hline Maximum load & $250 \mathrm{~kg}$ \\
\hline Combined error & $0.012 \%$ rated output \\
\hline Repeatability & $0.01 \%$ rated output \\
\hline
\end{tabular}

\section{Control Regime}

A proportional-integrative-derivative (PID) control scheme was prescribed using the thrust of the lab-scale motor as the feedback variable to maintain the motor thrust levels at a given set point. The derivative aspect of the control scheme is problematic in transient applications, as it is known to amplify higher frequency process noise that could cause large changes and oscillations in controller output. It has also been observed to cause "servo jitter" in similar applications, which justified the decision to only use the proportional-integral (PI) components of the controller (Peterson et al. 2012; Smith and Corripio 1985). Two primary criteria are considered when evaluating whether the given control scheme is functioning at a reasonable optimum state. The first is disturbance rejection, which is keeping the process variables at a given set point, and the second is command tracking, which refers to how well the controller tracks the command set point. The degree to which the controller tracks the command set point well is determined by rise time (the time it takes for the process variables to meet the command set point), settling time (the time required for the process variable to settle within a predetermined error band) and overshoot (the percentage the process variables overshoot the command set point) criteria.

Due to the transient nature of HRM combustion, a feed forward loop was employed in the controller to reject disturbances, mitigate transient effects and to counter the nonlinear flow characteristic. Although exclusive feed forward control might provide a faster response, it is difficult to implement given high levels of variability from one motor to another. Instead, a combination of feed forward and feedback control is proposed, with the feed forward aspect moving the valve quickly to a predetermined angle for a specified thrust, after which the feedback loop produces smaller, more precise changes until the thrust is within an acceptable range of the set point. The following methodology was followed in the development of the control scheme:

- Experimental performance data from the lab-scale HRM were analysed for thrust peak amplitude and settling time, from which a first-order plus dead time (FOPDT) model was derived. This was used to obtain initial controller tuning constants.

- A second-order transfer function was obtained graphically from results for previous pure-paraffin hot fire tests. This is an empirical description of a stable dynamic process and was used to verify the transfer function obtained from the simulator. 
- A mathematical model of the lab-scale rocket was used to simulate the system response from various inputs. The response was used to generate a final transfer function. The transfer function was compared to previous iterations and, if valid, used to find more precise controller tuning constants.

- A controller was designed and embedded into the code used to run and control the laboratory scale motor.

- Effects, such as nonlinearity of the valve flow characteristic, were considered and modifications were implemented into the controller. A simulation model of the hybrid rocket laboratory-scale motor was developed to predict suitable control parameters without the cost and time penalties of repeatedly making and firing laboratory-scale motors. In addition, to ensure accuracy and to obtain the approximate parameters of the controller, the FOPDT model was created from the step response observed in previous experimental test data. This also enabled comparison with the transfer function generated by the simulator so as to assess whether the parameters were within reasonable bounds. This required a simulated step response of the system. A FOPDT model transfer function is defined in Eq. 1 as follows:

$$
H(s)=\frac{K_{p} e^{-\theta_{D s}}}{1+\tau S}
$$

where $K_{p}$ is the process gain, $\tau$ is the process time constant, and $\theta$ is the process dead time. The process gain is calculated by the change in process output over the change in process input, or $\left(\frac{\Delta y}{\Delta \mathrm{u}}\right)$. The process time constant is calculated from the time needed for the output to reach $\left(1-e^{-1}\right)$ or $63.2 \%$ of steady state conditions, or formally put, if initial condition $y(0)=0$ and at time $t=\tau_{p}$ then Eq. 2 can be defined as:

$$
y\left(\tau_{p}\right)=\left(1-^{e-1}\right) K_{p} \Delta u=0.632 K_{p} \Delta u
$$

The process time delay is simply expressed as a time shift in the input variable.

Using the controller constants derived from the FOPDT model, the transfer function was further refined by graphically analysing the response from closed loop hot fire tests until the following, final transfer function, Eq. 3, was obtained:

$$
H(s)=\frac{12.788}{s^{2}+3.416 s+12.788}
$$

Using this function and a modified Ziegler-Nichols closed loop tuning scheme (Peterson et al. 2012), the controller constants were derived in order to suit the requirements of the control of the lab-scale motor.

\section{RESULTS}

\section{Open loop testing}

Control authority over the HRM was determined first before performing closed loop tests. The opening angle of the valve was correlated with the thrust produced by the motor so as to approximate the valve angle setting for a particular thrust measurement. This was also done to determine the control authority of the valve. Additionally, open loop testing was used to measure the noise from the thrust load cell from which a filter was designed.

Results from the open loop tests showed that from a fully open position $\left(90^{\circ}\right)$ to $65^{\circ}$, the valve angle had no effect on the thrust produced by the motor. This is shown in Fig. 8, where the red series is the measured thrust and the black series is the valve opening angle. A primary reason for this is that in that range there is excess oxidizer entering the chamber with a portion of it not reacting and thus only when the oxidizer is throttled sufficiently does the O/F ratio change enough to affect thrust output. This hypothesis is supported by the graph in Fig. 8, which shows a small increase in thrust just before the motor begins throttling down, indicating the possibility of an optimum $\mathrm{O} / \mathrm{F}$ ratio at that point.

From a control design perspective, it was helpful to first establish a relationship between the valve angle and thrust produced, and then create a feed forward component of the controller using a one-dimensional lookup table. Results are shown in Table 5 and illustrated in Fig. 9. Open loop testing also provided the throttle range within which the motor generated thrust could be safely modulated. This was predicted to be between 500 and $300 \mathrm{~N}$, but, as a precaution, a more conservative range of 310 to $490 \mathrm{~N}$ was selected. 


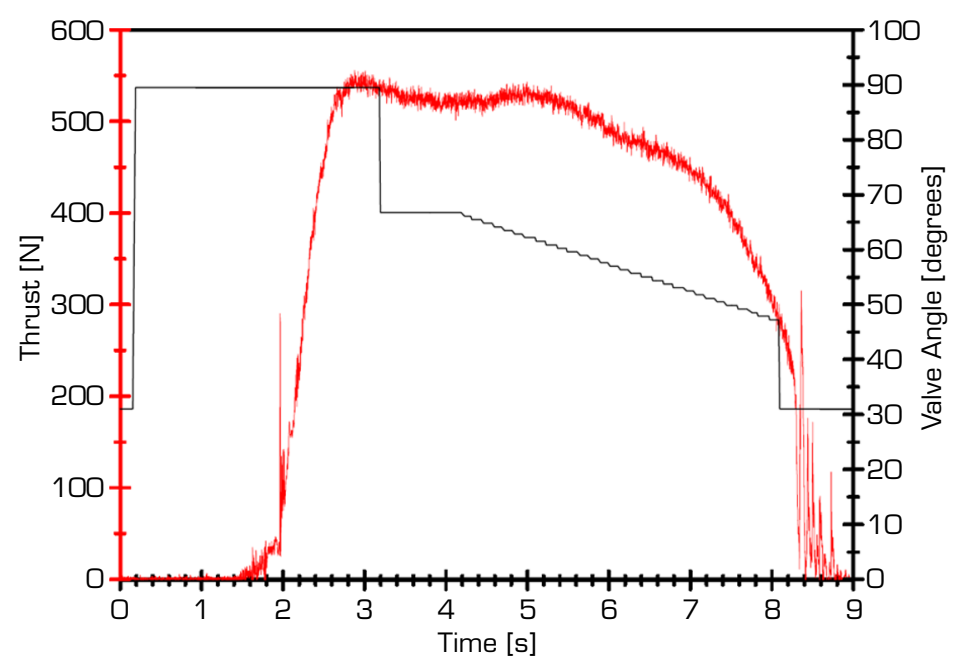

Figure 8. Open loop test result.

Table 5. Valve angle versus thrust, as predicted from open loop testing.

\begin{tabular}{cc}
\hline Valve Angle & Measured thrust \\
\hline $90^{\circ}$ & $530 \mathrm{~N}$ \\
\hline $65^{\circ}$ & $530 \mathrm{~N}$ \\
\hline $55^{\circ}$ & $490 \mathrm{~N}$ \\
\hline $50^{\circ}$ & $400 \mathrm{~N}$ \\
\hline $45^{\circ}$ & $300 \mathrm{~N}$ \\
\hline
\end{tabular}

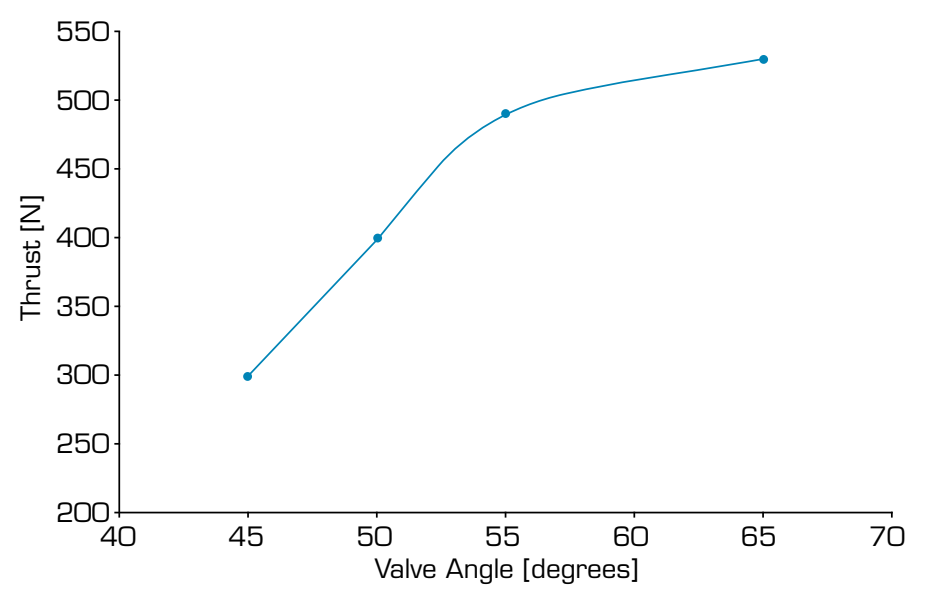

Figure 9. Valve angle versus thrust output obtained from open loop testing results.

The primary advantage gained from using a feed forward control scheme in conjunction with a feedback loop is that the speed and accuracy of the controller is increased. With the feed forward component, the controller has a means to arrive quickly at the desired thrust with only small changes needed to achieve a high degree of precision thereafter. However, an added complication in oxidizer feed systems that use blowdown pressurization is that of a decaying oxidizer flow rate as the pressure in the run tank decreases. As a result, the valve angle for a given thrust setting varies over time by a small amount. Moreover, HRM combustion is inherently transient and variable from one propulsion unit to another in terms of thrust produced, therefore a feedback component 
is still necessary for the controller to ensure the motor produces the thrust commanded. The closed loop testing described below utilized the feed forward lookup table along with a feedback loop.

\section{Closed loop testing}

Closed loop testing aimed to evaluate and validate the motor control scheme, as well as to estimate the general viability of throttling HRM for abovementioned applications. The performance of an unthrottled paraffin wax/ $\mathrm{N}_{2} \mathrm{O}$ motor obtained from hot fire testing is shown in Fig. 10. The thrust values slowly and continuously decrease throughout the length of the burn due to the shifting $\mathrm{O} / \mathrm{F}$ ratio and the decaying oxidizer tank pressure, which is characteristic of a blowdown hybrid motor where a single cylindrical port is used.

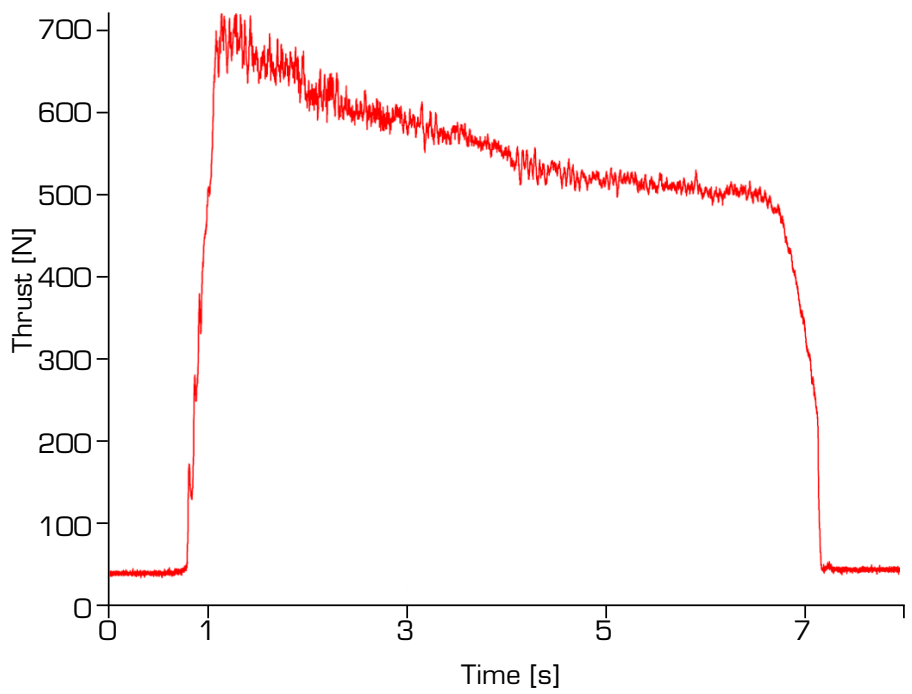

Figure 10. Unthrottled paraffin wax/ $\mathrm{N}_{2} \mathrm{O}$ hot fire test.

The results from several closed loop motor firings are given below, including successful and unsuccessful outcomes. These are given to illustrate the incremental improvement and eventual success in exercising control authority over the motor thrust profile. Figure 11 shows a test run with no feed forward control at all and only a feedback loop to coerce the thrust to the desired value. The thrust command profile was as follows: valve fully open for one and a half seconds to attain stability, throttle down to $490 \mathrm{~N}$ for $3 \mathrm{~s}$, throttle down further to $310 \mathrm{~N}$ for $3 \mathrm{~s}$, throttle up to $490 \mathrm{~N}$ for $4 \mathrm{~s}$ and then close the valve. The motor ignited successfully; however, the control system behaved erratically, most probably because the derivative term of the controller amplified the noise generated by the thrust load cell. The black data line represents the valve angle command variable, the red data are thrust measurements in newtons, and the blue line represents the desired thrust profile.

In Fig. 12, results are given for a test with improvements made to the controller, the derivative component was removed entirely, the sample rate was set to $250 \mathrm{~ms}$, and the proportional and integrative coefficients were left at 1.75 and 0.01 , respectively. Although results were still below expectation, the controller output was improved with no noticeable servo jitter and a more coherent command profile. The thrust profile upper limit was decreased from 490 to $480 \mathrm{~N}$, giving the following overall profile: valve open to $90^{\circ}$ for one and a half seconds, throttle to $480 \mathrm{~N}$ for $3 \mathrm{~s}$, throttle to $310 \mathrm{~N}$ for $3 \mathrm{~s}$, back up to $480 \mathrm{~N}$ until the total allowed burn time is reached.

The first stage of the profile worked as expected, the valve opened to maximum and it remained there for one and a half seconds (I). The controller then attempted to throttle down to $480 \mathrm{~N}$, which elicited a quick response from the controller, showing a significant amount of undershoot followed by oscillations in the controller output as the controller attempted to maintain the prescribed thrust level (II). This was due to the limited control authority of the valve and the significant effect that small changes in valve angle have on oxidizer mass flow rate. Experimental data and simulations from Zhao et al. (2018) have shown that a lag time in the motor response of a paraffin-wax motor exists, as the fuel regression rate cannot respond to the oxidizer flow rate change immediately. In the third stage (III), the command profile is given to throttle down to $310 \mathrm{~N}$. In the fourth and 
final stage (IV), the command is given to throttle the motor back up to $480 \mathrm{~N}$, but, as Fig. 12 shows, the natural thrust decay of the motor has once again caused the maximum possible thrust to drop below that of the thrust demanded and there is little that the controller can do to restore it.

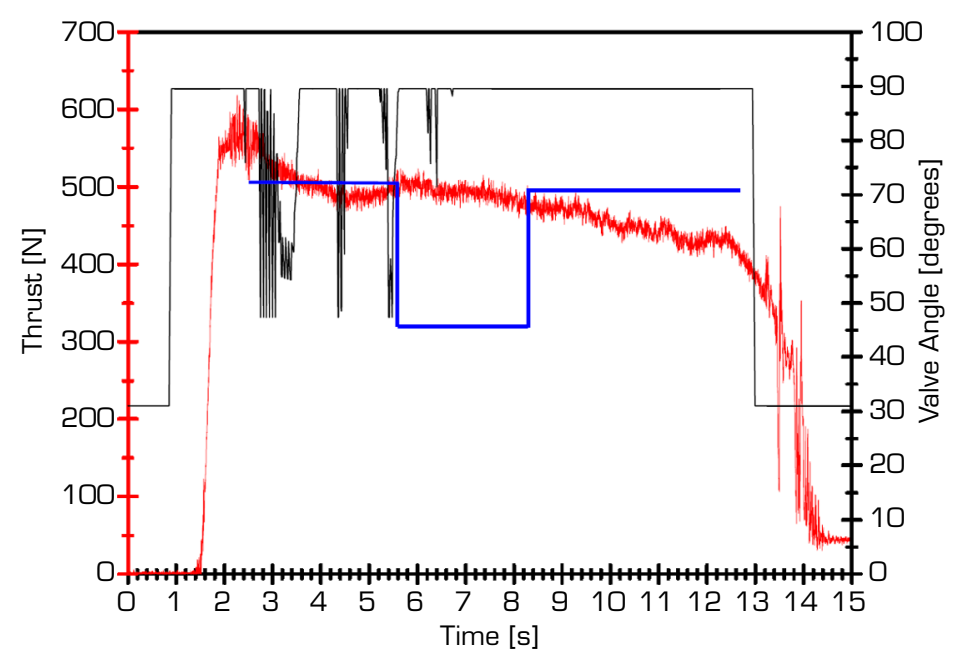

Figure 11. Sample test 1: valve angle and set-point profile superimposed over measured thrust.

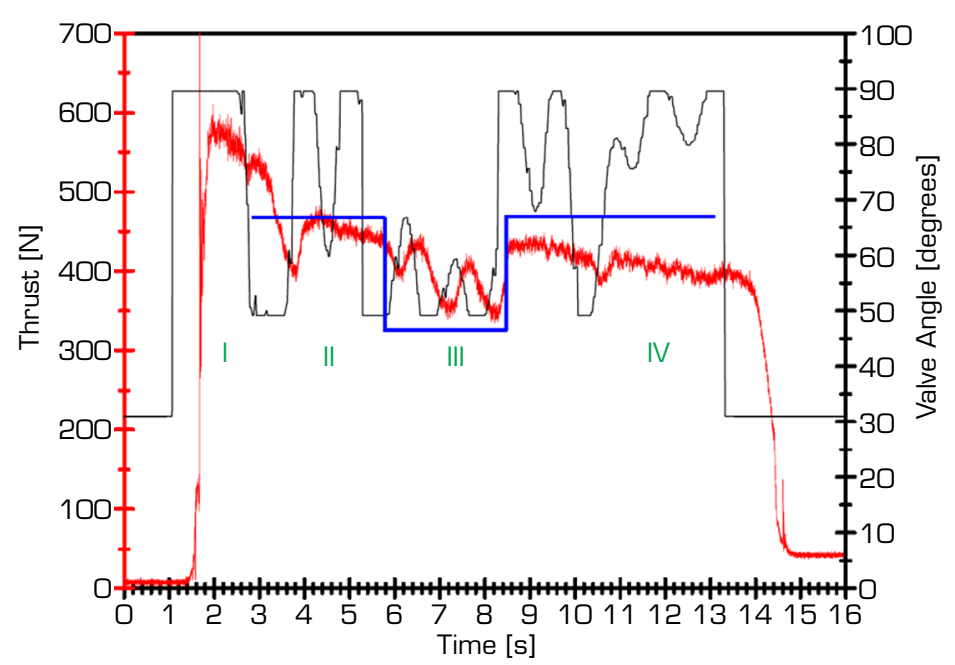

Figure 12. Sample test 2: valve angle and set-point profile superimposed over measured thrust.

These results illustrate one of the complexities of throttling a wax-based HRM. The valve angle limit, initially set at $47^{\circ}$ in this study, must be set low enough in accordance with the natural thrust profile of the motor. In this case, the thrust level would not drop below $350 \mathrm{~N}$, despite the valve operating in the lower boundary limit. The test was rerun, but with the valve programmed to open to $60^{\circ}$ before enabling throttling. Based on previous tests, an open loop control scheme with weak closed loop feedback was used to throttle the motor to a steady thrust of $370 \mathrm{~N}$. The valve angle corresponding to this thrust was determined from previous tests to be $46^{\circ}$. As seen in Fig. 13, the thrust initially peaks, as normal, followed by successful throttling down to the set point value of $370 \mathrm{~N}$. There is minor undershoot for about $2 \mathrm{~s}$, where after the thrust oscillated with a maximum amplitude of $10 \mathrm{~N}$ on either side of the set point until the motor was commanded to shut down. It can be seen that, when the ball valve reaches the predetermined angle of $46^{\circ}$, it oscillates very little on either side, reaching a maximum of $48^{\circ}$ and a minimum of $45^{\circ}$. The closed loop controller is restricted to move $\pm 5^{\circ}$ of the feed forward valve angle command (which in this test was $46^{\circ}$ ) to avoid unpredictable motor response. 
It is clear from these results that the throttling of high-regression rate, liquefying fuel HRMs are complicated by the natural variation in $\mathrm{O} / \mathrm{F}$ ratio through the burn, as the port diameter changes, and the oxidizer tank pressure decay. One obvious consequence is the slow initial response time seen in Fig. 13. It is likely that, when the throttling valve closes to its minimum allowable value, the oxidizer mass flow rate is still too high and therefore the $\mathrm{O} / \mathrm{F}$ ratio is not low enough to decrease the thrust to the set point quickly. As the port of the fuel grain expands over time, the $\mathrm{O} / \mathrm{F}$ ratio shifts low enough to reach the thrust set point and then allow for controllability. A solution to this is to lower the minimum allowable valve angle. The improvements made to the controller and its effects on command tracking are summarized on Table 6.

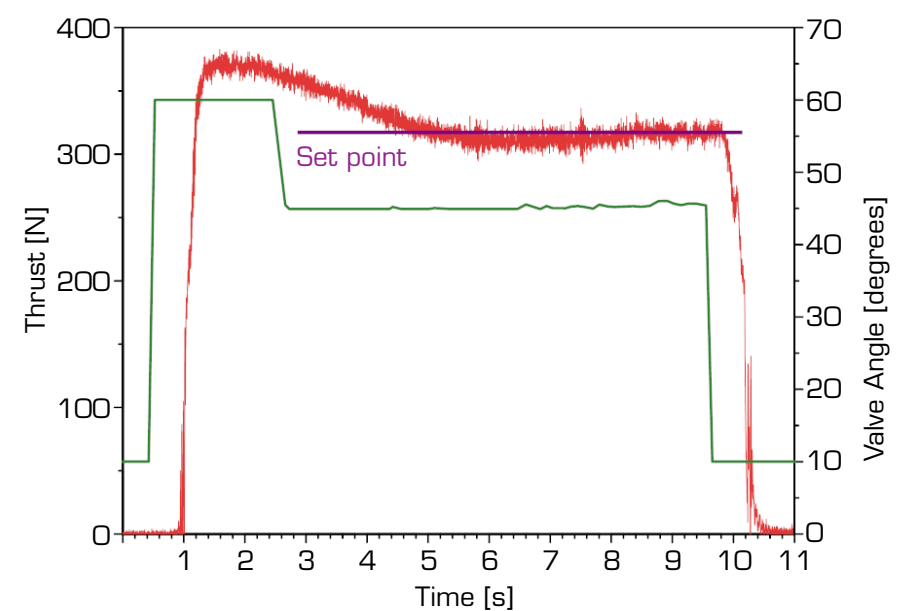

Figure 13. Sample test 3: thrust tracking set-point over time.

Table 6. Improvements made to the controller and its effects on command tracking.

\begin{tabular}{|c|c|c|c|c|}
\hline \multirow{2}{*}{ Test } & \multicolumn{3}{|c|}{ PID parameters } & \multirow{2}{*}{ Command tracking } \\
\hline & $\mathbf{P}$ & $\mathbf{I}$ & $\mathbf{D}$ & \\
\hline Sample test 1 & 1.75 & 0.01 & 0.004 & $\begin{array}{l}\text { Unable to track commands. Noise affects derivative } \\
\text { function and sample rate too high }\end{array}$ \\
\hline Sample test 2 & 1.75 & 0.01 & 0 & Poor. Varied between 6 and $15 \%$ from set point \\
\hline Sample test 3 & \multicolumn{3}{|c|}{$\begin{array}{c}\text { Feed forward control with weak } \\
\text { feedback: P: } 1.25 \\
\text { I: } 0.01 \text { only allowed to operate within } \\
5^{\circ} \text { of feed forward parameters }\end{array}$} & $\begin{array}{c}\text { After } 5 \mathrm{~s} \text {, the motor remains within } 2.4 \% \text { of the } \\
\text { maximum thrust of the motor. }\end{array}$ \\
\hline
\end{tabular}

In Fig. 14, results are given for a test in which the set point was reduced to $370 \mathrm{~N}$ for $4 \mathrm{~s}$ and then steadily increased to $410 \mathrm{~N}$ over the remaining $4 \mathrm{~s}$ of the burn. As before, the valve opened to $60^{\circ}$ for the first one and a half seconds, after which the controller attempted to throttle the motor to $370 \mathrm{~N}$. As in Fig. 13, the thrust level decreased very slowly, even though the valve angle was set to the minimum allowable value. After the valve reached its minimum angle value, a few minor oscillations can be seen, which were attributed to noise from the thrust load cell value. Approximately $5 \mathrm{~s}$ into the burn, the thrust variable dipped below the set point line, which subsequently caused the controller to begin opening the valve. When the valve angle reached $45^{\circ}$, the thrust output became noisy and unresponsive. Although the average thrust did steadily increase at the same rate as the set point value, the thrust remained offset from the set point, despite the valve angle increasing accordingly. It is thought that, when the control valve began to open to throttle up the motor, the $\mathrm{O} / \mathrm{F}$ ratio shifted too high and caused various combustion instabilities and uneven burning, which resulted in an unsteady thrust output. It is also hypothesized that at the end point of the burn, the pressure in the run tank dropped considerably and may have been in the gaseous phase prior to the injector, altering the behaviour of the injected gases. Figure 15 shows the pressure before the injector at the end of the burn ramped up slightly, corresponding to the valve angle opening, and thereafter remained steady at 43 bar. 


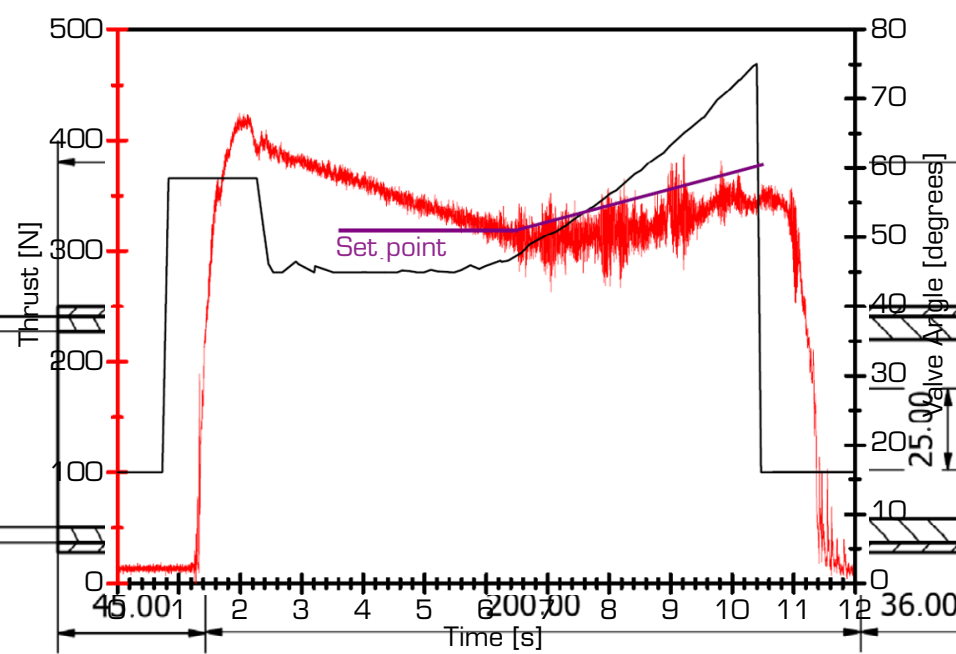

Figure 14. Varying set-point and valve angle superimposed over measured thrust. The valve angle opening at a steadily higher rate since the measured thrust variable is offset from the set point.

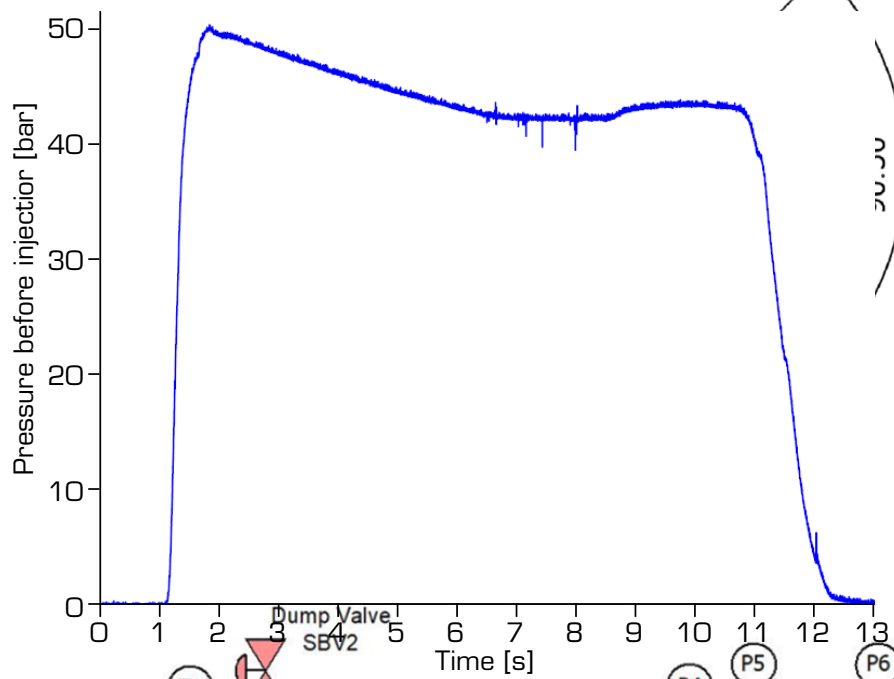

Figure 15. Oxidizer pressure before injector for ramp set point test showing low pressure at the end of the burn, which may be the cause of instabilities recorded for this test.

This study is also concerned with testing of throttling systems that can be rapidly moved from the laboratory to the launch pad and implemented with minimum adaptation. Consequently, any control scheme must be operable in a flight vehicle where thrust measurements are not available, as they are on a static test stand. Fortunately, combustion chamber pressure correlates very well with thrust in HRMs (Peterson et al. 2012, Velthuysen 2018), providing an opportunity to replace thrust as the control feedback parameter in the control scheme. Figure 16 provides data from a laboratory scale test in which the measured combustion chamber pressure is used in place of load cell force so as to assess the control response of the system. Initially, the relationship between chamber pressure and thrust output can be empirically estimated to an acceptable degree of accuracy from graphical analysis of past hot fire tests.

For the data in Fig. 16, the pressure command given by the controller was 24 bar for 4 s, followed by a step-down to 22 bar for a further $4 \mathrm{~s}$, where after the motor was commanded to shut off. Calculations estimated that, at 24 bar, the motor would achieve $330 \mathrm{~N}$ of thrust and, at 22 bar, $310 \mathrm{~N}$. Again, the motor was slow to respond and only accurately tracked the pressure set point after $5 \mathrm{~s}$, but the test showed that successful control of an HRM is possible using chamber pressure as the feedback parameter. The implementation of a similar control scheme on a flight-weight vehicle requires experimental data from which to construct a lookup table for feed forward control. A correlation between combustion chamber pressure and thrust also needs to be determined. 


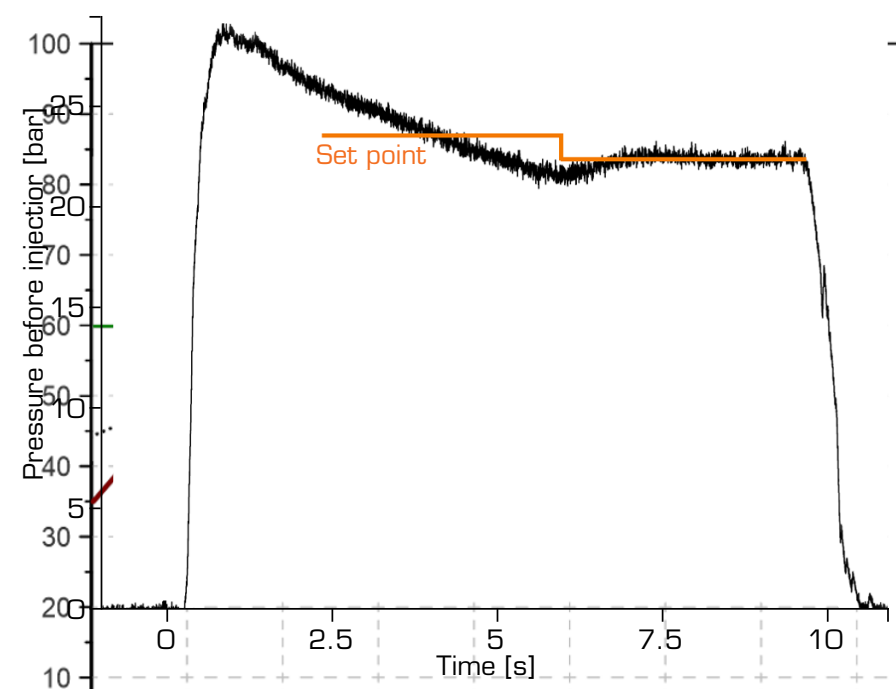

Figure 16. Chamber pressure tracking a set-point in closed loop pressure test. The orange lines represent the set point values that the controller was commanded to track.

\section{CONCLUSION}

Thrust modulation of a high-regression rate, liquefying fuel HRM has been demonstrated using a low-cost through-port ball valve as the controlling element. The control authority of such valves is restricted, however, and only enable throttling at the very lower limits of the allowable valve angle opening range. Control is further complicated by the natural shift in $\mathrm{O} / \mathrm{F}$ ratio that occurs as the liquefying fuel grain depletes and the port diameter increases. This means that control over the motor is limited and somewhat difficult to achieve when small changes in valve angle produce large changes in thrust. Due to the nonlinear flow characteristic inherent in ball valves, the controller requires additional features, such as the feed forward lookup table implemented in this study. Nonetheless, throttling of high-regression rate liquefying fuel HRMs is possible, as shown here, and offers a potentially useful method of energy control during the launch of high-altitude hybrid rockets, including those used in suborbital sounding applications. Throttling HRMs using combustion chamber pressure as a feedback variable was also demonstrated, thereby allowing controller integration into hybrid launch vehicles. Further research is needed to improve throttling response of paraffin wax $/ \mathrm{N}_{2} \mathrm{O} \mathrm{HRMs}$, and to better understand the instabilities produced when attempting to throttle-up such motors.

\section{AUTHORS' CONTRIBUTION}

Conceptualization: Brooks M, Pitot J and Velthuysen T; Methodology: Velthuysen T; Investigation: Velthuysen T; Software: Velthuysen T; Writing - Original Draft: Velthuysen T; Writing - Review and Editing: Brooks M and Pitot J; Funding Acquisition: Brooks M; Resources: Brooks M and Pitot J.; Supervision: Brooks M and Pitot J.

\section{DATA AVAILABILITY STATEMENT}

All data sets were generated or analysed in the current study 


\section{FUNDING}

National Research Foundation of South Africa

Grant No. 106940

\section{ACKNOWLEDGEMENTS}

Not applicable.

\section{REFERENCES}

Altman D, Holzman A (2007) Overview and History of Hybrid Rocket Propulsion. In: Kuo KK, Chiaverini MJ, editors. Fundamentals of Hybrid Rocket Combustion and Propulsion. Reston: AIAA. p. 1-33. https://doi.org/10.2514/5.9781600866876.0001.0036

Arves J, Gnau M, Joiner K, Kearney D, McNeal C, Murback M (2003) Overview of the Hybrid Sounding Rocket (HYSR) Project. Paper presented 39th AIAA/ASME/SAE/ASEE Joint Propulsion Conference and Exhibit. AIAA; Huntsville, Alabama, United States of America. https://doi.org/10.2514/6.2003-5199

Bouziane M, Bertoldi AEM, Milova P, Hendrick P, Lefebvre M (2019) Performance comparison of oxidizer injectors in a 1-kN paraffin-fueled hybrid rocket motor. Aerosp Sci Technol 89:392-406. https://doi.org/10.1016/j.ast.2019.04.009

Brooks M, Pitot J, Chowdhury S, Genevieve B, Roberts L (2010) Introduction to the University of KwaZulu-Natal Hybrid Sounding Rocket Program. Paper presented 46th AIAA/ASME/SAE/ASEE Joint Propulsion Conference \& Exhibit. AIAA; Nashville, Tennessee, United States of America. https://doi.org/10.2514/6.2010-7118

Doran E, Dyer J, Marzoña M, Karabayaglu A, Zilliac G, Mosher R, Cantwell B (2009) Status Update Report for the Peregrine Sounding Rocket Project: Part III. 45th AIAA/ASME/SAE/ASEE Joint Propulsion Conference \& Exhibit. AIAA; Denver, Colorado, United States of America. https://doi.org/10.2514/6.2009-4840

Duban P (1968) La fusée sonde LEX. Aéronautique et Astronautique. pp. 47-54. [accessed Feb 06 2018]. http://eurospace. free.fr/lex.html

Kniffen R, McKinney B, Estey P (1990) Hybrid rocket development at the American Rocket Company. Paper presented 26th Joint Propulsion Conference. AIAA; Orlando, Florida, United States of America. https://doi.org/10.2514/6.1990-2762

Maharaj CS (2018) Performance Characterisation of Metal Additives in Paraffin Wax Hybrid Rocket Fuel Grains (Master thesis). Durban: University of KwaZulu-Natal. In English.

Mazzetti A, Merotto L, Pinarello G (2016) Paraffin-based hybrid rocket engines applications: A review and a market perspective. Acta Astronaut 126(1):286-297. https://doi.org/10.1016/j.actaastro.2016.04.036

Mead Junior FB, Bornhorst BR (1969) Certification Tests of a Hybrid Propulsion System for the Sandpiper Target Missile. AFRPL-TR-69-73. Department of Defense of United States of America. Defense Technical Information Center. [accessed Jun 16 2017]. https://apps.dtic.mil/sti/citations/AD0503586

Parissenti G, Pessana M, Gaia E, Zaccagnino E, Santilli F, Pavarin D, Bettella A, Ronningen J-E, Van Put P, Tijsterman R, et al. (2011). Throttleable hybrid engine for planetary soft landing. Paper presented 4th European Conference for Aerospace Sciences (EUCASS 2011). EUCASS; Saint Petersburg, Russia. 
Penn CD, Branigan JE (1975) Preliminary Flight Tests of the HAST Propulsion System. AFRPL-TR-15-5. Air Force Systems Command. United States Air Force. [accessed Jun 14 2017]. https://apps.dtic.mil/dtic/tr/fulltext/u2/a012200.pdf

Peterson ZW, Eilers S, Whitmore S (2012) Closed-Loop Thrust and Pressure Profile Throttling of a Nitrous Oxide HTPB Hybrid Rocket Motor. Paper presented 48th AIAA/ASME/SAE/ASEE Joint Propulsion Conference \& Exhibit. AIAA; Atlanta, Georgia, United States of America. https://doi.org/10.2514/6.2012-4200

Ruffin A, Barato F, Santi M, Paccagnella E, Bellomo N, Miste G, Venturelli G, Pavarin D (2017) Development of a Cavitating Pintle for a Throttleable Hybrid Rocket Motor. Paper presented 7th European Conference for Aeronautics and Aerospace Sciences. EUCASS; Milan, Italy.

SASOL. Microcrystalline Wax: SASOLWAX 0907. Products SASOL. [accessed Mar. 05 2017]. https://products.sasol.com/pic/ products/home/grades/AS/5sasolwax-0907/index.html

Smith CA, Corripio AB (1985) Principles and Practice of Automatic Process Control. New Jersey: John Wiley \& Sons.

Spurrier ZS (2016) Throttleable GOX/ABS Launch Assist Hybrid Rocket Motor for Small Scale Air Launch Platform (Master thesis). Logan: Utah State University. In English.

Sutton G, Biblarz O (2001) Rocket Propulsion Elements. Canada: John Wiley \& Sons.

Velthuysen T (2018) Closed-loop Throttle Control of a Hybrid Rocket Motor (Master thesis). Durban: University of KwaZuluNatal. In English.

Wang Z, Lin X; Li F, Yu X (2020) Combustion performance of a novel hybrid rocket fuel grain with a nested helical structure (Master thesis). Aerosp Sci Technol 97:105613.

Whitmore SA, Peterson ZW, Eilers SD (2014) Closed-Loop Precision Throttling of a Hybrid Rocket Motor. J Propul Power 30(2):325-336. https://doi.org/10.2514/1.B34924

Wu Y, Yu X; Lin X; Li S; Wei X, Zhu C; Wu L (2018) Experimental investigation of fuel composition and mix-enhancer effects on the performance of paraffin-based hybrid rocket motors. Aerosp Sci Technol 82-83:620-627. https://doi.org/10.1016/j. ast.2018.09.026

Zhao B, Yu N, Liu Y, Zeng P, Wang J (2018) Unsteady simulation and experimental study of hydrogen peroxide throttleable catalyst hybrid rocket motor. Aerosp Sci Technol 76:27-36. https://doi.org/10.1016/j.ast.2018.02.008 